
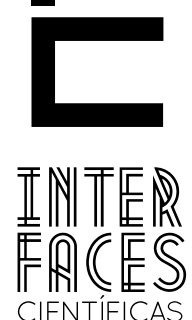

HUMANASE SOCIAIS

\title{
REPOSITÓRIO INSTITUCIONAL: UMA PROPOSTA PARA A GESTÃO DA INFORMAÇ̃̃O CIENTíFICA DA IES DO SENAI BAHIA
}

Rita De Cássia Machado Da Silva ${ }^{1}$ Flávia Garcia Rosa ${ }^{3}$
Cristiane de Magalhães Porto ${ }^{2}$

\section{RESUMO}

Os repositórios institucionais são ambientes virtuais adequados para atender às necessidades informacionais de armazenamento, aquisição, produção e compartilhamento da informação. 0 objetivo deste trabalho é apresentar o projeto e refletir sobre as etapas de implantação do repositório das Faculdades de Tecnologia do SENAI-Bahia com o intuito de promover a gestão da informação científica produzida pela instituição. 0 desenvolvimento deste projeto teve como base a experiência bem sucedida do Repositório da UFBA, utilizando como referência o modelo de suas políticas, assim como a metodologia utilizada para o seu desenvolvimento, sendo estes, a pesquisa-ação; a aplicação de questionários; entrevistas e a observação participativa. Assim, esta proposta possibilitará que os profissionais responsáveis pelo tratamento e provimento de acesso ao acervo digital possam utilizar uma ferramenta que venha a contribuir com a ampliação da visibilidade da instituição em nível global e aumente o impacto dos resultados de pesquisa.

\section{PALAVRAS-CHAVE}

Repositório Institucional. Gestão do Conhecimento Científico. Comunicação Cientifica. Acesso Aberto. 


\section{ABSTRACT}

Institutional repositories are virtual environments suited to meet the informational needs to store, purchase, produce and share information. The aim of this paper is to present the project and reflect on the stages of implementation of the repository of Colleges of Technology SENAI-Bahia in order to promote the management of scientific information produced by the institution. The development of this project was based on the successful experience of the repository of the university, using as reference the model of its policies, as well as the methodology for their development, known as action research, the use of questionnaires, interviews and the participant observation. Thus, this proposal will enable the professionals who are responsible for treatment and for the access to the digital archive to use a tool that will contribute to broaden the visibility of the institution at the global level and increase the impact of search results.

\section{KEYWORDS}

Institutional Repository. Management of Scientific Knowledge. Scientific Communication. Open Access.

\section{INTRODUÇÃO}

Ao se considerar o número crescente de publicações de trabalho científicos disponibilizados na internet, verifica-se que o meio eletrônico está sendo cada vez mais utilizado pelas comunidades científicas para a aquisição e construção de informações. Sendo assim, não podemos deixar de tratar estas informações a fim de permitir não apenas uma recuperação eficiente, mas também de possibilitar a geração de novas informações e disponibilizá-las para um uso futuro, além da preservação da memória.

\section{RESUMEN}

Los repositorios institucionales son ambientes virtuales adecuados para atender a las necesidades informacionales de almacenamiento, adquisición, producción y compartimiento de información. El objetivo de este trabajo es presentar el proyecto y reflexionar sobre las etapas de implantación del repositorio de las Facultades de Tecnología del SENAI-Bahia con la intención de promocionar la gestión de la información científica producida por la institución. El desarrollo de este proyecto tuvo como base la experiencia exitosa del Repositorio de la UFBA, utilizando como referencia el modelo de sus políticas bien como la metodología utilizada para su desarrollo, siendo estos: la investigación-acción; la aplicación de cuestionarios; entrevistas y observación participativa. De esta manera, esta propuesta posibilitará que los profesionales responsables por el tratamiento y proveimiento de acceso al acervo digital puedan utilizar una herramienta que aporte a la ampliación de la viabilidad de la institución en nivel global e incremente el impacto de los resultados de investigación.

\section{PALABRAS CLAVE}

Repositorio Institucional. Gestión del Conocimiento Científico. Comunicación Científica. Acceso Abierto.

A Instituição de Ensino Superior (IES) do Serviço Nacional de Aprendizagem Industrial (SENAI) - Bahia busca implantar um repositório institucional (RI) para disseminar e preservar os trabalhos científicos produzidos na Instituição pelos alunos, professores e pesquisadores e, assim, possibilitar a sua disseminação, tornando-os acessíveis ao nível nacional e internacional.

Os repositórios institucionais (RI) surgem associados ao movimento de acesso livre como uma estratégia 
eficaz de melhoria das condições de disponibilidade e facilidade de acesso à produção intelectual, acadêmica e científica dos centros produtores de conhecimento, como as universidades e centros de investigação, constituindo um elo na rede dos atores com intervenção no campo da comunicação científica.

\begin{abstract}
O Repositório é um sistema de informação disponível em um ambiente digital destinado a gerenciar a produção científica de uma instituição, cuja ênfase é atender às necessidades de coletar, armazenar, organizar, preservar, recuperar e, sobretudo, disseminar amplamente as publicações e os materiais de ensino produzidos pelos pesquisadores, alunos e professores da Instituição (IBICT, 2011, online).
\end{abstract}

Esse é um ambiente que surge para atender às necessidades informacionais de armazenamento, aquisição, produção e compartilhamento da informação. $E$, assim, oferecer as vantagens de: visibilidade da instituição, interoperabilidade de dados, controle e armazenamento da produção científica institucional, preservação da informação em longo prazo, autoarquivamento, acesso livre, intercâmbio de informação entre as instituições universitárias e de pesquisa como também proporcionar melhoria na qualidade dos trabalhos científicos e minimização dos custos de publicação.

Esse trabalho tem como objetivo geral apresentar e refletir sobre a implantação do repositório da IES do SENAI-Bahia para divulgar a sua produção científica, tornando possível a interação entre o repositório e os serviços de apoio aos docentes e alunos.

Os objetivos específicos são:

- Contribuir para ampliar a visibilidade da Instituição a partir do uso do repositório institucional;

- Permitir o acesso livre (preservados os direitos do autor) ao acervo das produções científicas;
- Possibilitar a difusão de uma coleção original;

- Ser uma ferramenta educacional tendo compromisso com a produção de materiais didáticos (monografias, dissertações, teses, artigos, vídeos e imagens).

Ao refletir sobre a importância dos repositórios institucionais em promover a partilha, a (re)utilização de recursos e objetos educacional, observa-se que as comunidades de prática (bibliotecas, colegiados, Núcleos de Aprendizagem a Distância (NEAD), sistemas de informação, publicações e gestão de registros) têm um papel importante em seu desenvolvimento e manutenção.

Para Meadows (1999, p. 132), “as bibliotecas possuem duas funções básicas: atuar como um arquivo de publicações e torná-las disponíveis para os leitores". Elas são como espaço de múltipla comunicação, um centro irradiador dos saberes acadêmicos e não acadêmicos caracterizados como instituição social. Pode-se ressaltar que os profissionais da informação e a biblioteca são de grande importância para atuar junto aos repositórios institucionais, promovendo a disseminação científica e favorecendo o intercâmbio de informações entre a comunidade científica.

A partir destas considerações, este trabalho busca evidenciar a importância em implantar um repositório científico na IES do SENAI-BA para que possa divulgar toda publicação científica realizada na Instituição, tanto por parte dos docentes e investigadores quanto dos discentes, na busca de solucionar problemas na organização das informações, facilitando a sua disseminação e recuperação.

Utilizaremos como referência o modelo dos documentos que define as políticas do Repositório Institucional da Universidade Federal da Bahia (UFBA) e a mesma metodologia utilizada para o seu desenvolvimento, sendo, a pesquisa-ação, o estudo de caso e aplicação de questionários e entrevistas assim como 
a observação participativa, o que será adotado para este estudo. (ROSA, 2010)

Esta pesquisa é classificada como pesquisa-ação, pois, segundo Gil (2010), sua metodologia promove a intervenção, o desenvolvimento e a mudança na esfera dos grupos, organizações e comunidades. Este tipo de pesquisa busca diagnosticar um problema específico numa situação específica com o objetivo de alcançar um resultado prático. Ainda para Gil (2010), a pesquisa-ação difere dos outros tipos de pesquisa porque ocorrem, em diversos momentos desta, o envolvimento e a ação dos pesquisadores com os grupos interessados. Neste caso, para a implantação do repositório é necessário o envolvimento entre os bibliotecários, gestores, professores, pesquisadores, alunos e coordenadores de cursos com o propósito de resolver os problemas enfrentados na organização da informa- ção e possibilitar a sua recuperação e disseminação em âmbito internacional.

Esta pesquisa será baseada na iniciativa da UFBA que tem seu repositório em atividade desde setembro de 2010 e venceu o concurso promovido pelo Instituto Brasileiro de Informação em Ciência e Tecnologia (IBCT) como o repositório institucional brasileiro que teve o maior número de depósitos de artigos científicos de maio a outubro de 2011: foram cerca de 2,5 mil inserções (ANDRADE, 2011).

Serão apresentados a seguir alguns aspectos importantes para esclarecimento, tais como, levantamento de informações sobre repositórios, o Dspace, acesso aberto, políticas de arquivamento e os resultados esperados da sua utilização para a organização desta informação.

\section{A DISSEMINAÇÃO DA PRODUÇ̃̃O CIENTÍFICA E A PRESERVAÇ̃̃O DA MEMÓRIA INSTITUCIONAL}

A tecnologia digital tem expandido a acessibilidade dos trabalhos acadêmicos. Além da tradicional publicação em livros, revistas e jornais, os pesquisadores agora podem disseminar seus trabalhos utilizando também os meios digitais, por meio de listas, páginas da web, repositórios digitais e periódicos on-line. Dooley (1999 apud BURKE, 2003, p. 133) já acreditava que "difundir a informação era uma arma politicamente mais eficaz do que suprimi-la”. A partir desta afirmação, entende-se que a instituição precisa tornar a informação pública para atingir seus propósitos, além de possibilitar uma ampla disseminação e preservação da produção científica por ela desenvolvida. Deste modo, pode- se considerar que o repositório é uma ferramenta que possibilita à instituição alcançar estes objetivos. Esta preocupação é recente, quando

\begin{abstract}
Uma nova economia surgiu em escala global no último quartel do século XX. Chamo-a de informacional, global e em rede [...] É Informacional porque a produtividade e a competitividade de unidades ou agentes nessa economia (sejam empresas, regiões ou nações) dependem basicamente de sua capacidade de gerar, processar e aplicar de forma eficiente a informação baseada em conhecimentos. É global porque as principais atividades produtivas, o consumo e a circulação, assim como seus componentes (capital, trabalho, matéria-prima, administração, informação, tecnologia e mercados) estão organizados em escala global, diretamente ou mediante uma rede de conexões entre agentes econômicos. É rede porque, nas novas condições históricas, a produtividade é gerada, e a concorrência é feita em uma rede global de interação entre redes empresariais. (CASTELLS, 1999, p. 120)
\end{abstract}

Observa-se que a revolução da tecnologia da informação e a reestruturação do capitalismo introduziram uma nova forma de sociedade, a sociedade em rede. 
Essa sociedade é caracterizada pela globalização das atividades econômicas decisivas, do ponto de vista estratégico, por sua forma de organização em redes, pela flexibilidade e instabilidade do emprego, pela individualização da mão de obra e por uma cultura de virtualidade real construída a partir de um sistema de mídia onipresente interligado e altamente diversificado.

Com a implantação do repositório, a disseminação e o acesso aos trabalhos científicos passam a ser garantidos assim como aumenta as oportunidades de busca avançada e proporciona novas descobertas. Segundo Castells (1999, p. 142), as atividades de serviços informacionais "produzem e distribuem com base na informação e em conhecimento incorporados no processo de trabalho pelo poder cada vez maior das tecnologias da informação".

A influência no uso das tecnologias da informação e comunicação (TIC) é verificada em todas as áreas da sociedade, seja na vida social, no trabalho, no lazer e até mesmo nas relações entre os indivíduos. As mudanças ocorridas na economia mundial favoreceram a formação de redes virtuais, modificando os hábitos

\subsection{REPOSITÓRIO E O ACESSO À INFORMAÇ̃̃O CIENTÍFICA}

Os repositórios institucionais são ambientes que possibilitam armazenar o material em formato digital e têm a capacidade de preservar e gerir o seu conteúdo por um longo período de tempo proporcionando a acessibilidade, a interatividade e possibilitando a difusão da informação e do conhecimento entre seus usuários. Bautier (1968 apud BURKE, 2003) já sinalizava que, à medida que a informação aumentava de volume, os registros passaram a precisar de repositórios especiais para a guarda e recuperação da informação. Segundo Pieracciani (2008, p. 100), “[. . .] o desafio está em criar ou descobrir o conhecimento existente; compilar esse conteúdo de forma organizada e fazê-lo chegar a quem fará uso dele [...]". sociais que criam novas formas de interação entre os indivíduos. Esta é uma economia baseada no conhecimento e na socialização em rede que ultrapassa as fronteiras territoriais e favorecem a globalização. Philip Kotler, em uma entrevista concedida à revista HSM, afirma que "Fenômenos como globalização e digitalização introduziram uma nova dimensão de velocidade e interdependência em nossas vidas. Não há retorno possível" (SALIBI NETO, 2009). Esta afirmação nos faz perceber que a dependência imposta pelas TIC estará constantemente presente em nossas vidas.

Neste contexto, a informação e o conhecimento tornaram-se imprescindíveis para o crescimento da sociedade e as TIC tiveram um papel importantíssimo nesta era da informação, pois favoreceu de forma radical a transformação na estrutura e organização do trabalho e das profissões. Em consequência disso, o mercado de trabalho passou a exigir novos níveis de qualificação profissional que devem estar sempre antenados às inovações; os serviços tradicionais passam a ser automatizados e surgem novos serviços para atender as demandas da automatização dos processos.

Os gestores da informação passaram a se preocupar mais com a necessidade da centralização e organização dos documentos para permitir a recuperação da informação de forma ágil e eficaz. Com isso, os documentos produzidos pela instituição deixariam de ser uma propriedade privada e passaram a ser considerados Institucionais. No caso de instituições universitárias, as informações científicas eram acessadas por meio de publicações acadêmicas como revistas, livros, monografias, teses e dissertações no formato impresso, como também eram trocadas entre os pares, inicialmente por meio de correio ou em encontros nos cafés com conversas informais, que ficaram sendo conhecidos no meio acadêmico como "colégios invisíveis". 
Com a evolução das tecnologias de comunicação, se tornou mais fácil e rápido os pesquisadores passarem a trocar informações de maneira síncrona ou assíncrona no formato digital e/ou eletrônico, ou seja, a transmissão da informação passou a ser bem mais rápida e, em muitos casos, em tempo real independente da distância entre os pesquisadores. Para Burke (2003, p. 160), “além da geografia, também a sociologia das bibliotecas é relevante para a história da aquisição do conhecimento. 0 acesso às primeiras bibliotecas modernas dependia das atitudes do bibliotecário e de sua equipe".

As novas formas de transferência da informação e dos diversos meios de comunicação por meio de tecnologias digitais possibilitam as bibliotecas expandirem a acessibilidade dos trabalhos acadêmicos tornando-os mais visíveis a nível internacional. Sendo assim, os alunos, professores e pesquisadores, além do acesso a publicação tradicional em meios impressos, poderão agora dispor de um lugar comum para distribuir suas publicações entre os pares por intermédio dos meios eletrônicos, incluindo e-mails, listas, páginas da web, revistas on-line e também dos repositórios digitais. Sendo este uma grande contribuição para a ciência, que segundo Castells (1999 p. 166), “[. . . ] estão organizadas em campos específicos de pesquisa, estruturadas em redes de pesquisadores que interagem por intermédios de publicações, conferências, seminários e associações acadêmicas".

\subsection{REPOSITÓRIO INSTITUCIONAL: UM AMBIENTE FAVORÁVEL Á INOVACÃO NO SISTEMA DE COMUNICACÃO CIENTÍFICA}

A inovação vem sendo um verdadeiro desafio a ser enfrentado pela grande maioria das Instituições, exigindo, assim, iniciativas que venham a atender às demandas dos clientes internos e externos. Nas instituições científicas isso não ocorre de maneira diferente. Para Burke (2003, p. 105), “a inovação in-
Burke (2003, p. 162) diz que "[. . . ] os lugares-comuns ajudavam os escritores a produzir novos textos e os leitores a assimilá-los com o mínimo esforço". Pensando no repositório institucional como um "lugar comum", podemos dizer que este é um ambiente contemporâneo onde os pesquisadores poderão disponibilizar seus trabalhos com a garantia de que será acessado e preservado por tempo indeterminado. 0 autor também afirma que os "lugares comuns" possibilitam ao pesquisador organizar a informação e recuperá-la com agilidade no momento que precisar utilizá-la.

Segundo Costa e Leite (2009), o RI é uma poderosa alternativa que, do ponto de vista da disponibilidade e acesso total à informação, potencializa a produção do conhecimento enquanto que, do ponto de vista da disseminação da informação, proporciona a visibilidade da instituição e maximiza o impacto dos resultados de pesquisa por meio da ampliação de seu acesso.

O repositório é um ambiente que oferece serviços de informação científica, destinado a gerenciar a produção científica e/ou acadêmica de uma instituição sendo elas Universidades ou Instituto de Pesquisa (COSTA; LEITE, 2009). Desta maneira, a Instituição irá promover um lugar comum à aprendizagem e incentivar a leitura que servirá de apoio ao desenvolvimento da pesquisa e de novas descobertas. Com isso, proporcionar à instituição divulgar seus trabalhos tornando- se conhecida perante a comunidade científica a nível nacional e internacional.

telectual, mais que a transmissão da tradição, é considerada uma das principais funções das instituições de educação superior [. . . ]", onde a contribuição ao conhecimento é estimulada pela interação entre os pesquisadores acadêmicos das mais diversas áreas do conhecimento. 
Desta maneira, pode-se considerar o repositório institucional como um importante instrumento que contribui com a inovação no sistema de comunicação científica, pois, possibilita esta interação e proporciona a gestão do conhecimento científico. Em relação a esta gestão, observa-se que:

\begin{abstract}
Por se tratar de uma metodologia e de uma sistematização de dados, informações e conhecimento, a gestão do conhecimento envolve ações de identificação, coleta, armazenamento/catalogação, disponibilização, compartilhamento, adaptação e uso de informação [... ]. (HOMMERDING; VERGUEIRO, 2004, p. 32)
\end{abstract}

Para entender melhor sobre o tema inovação, o Manual de Oslo (1997) descreve que uma inovação tecnológica é considerada e implantada se tiver sido introduzida no mercado (inovação de produto) ou usada no processo de produção (inovação de processo). Seguindo este raciocínio, entende-se que o reposi- tório é uma inovação empregada no processo. Ele está inserido em várias partes do ambiente empresarial onde ocorre a inovação. Na Figura 1, Pieracciani (2008) usa a metáfora de uma lâmpada como proposta de adoção de um método para fazer o diagnóstico da instituição, avaliando o quanto ela é inovadora e o que a faz ser inovadora.

Assim, se observa que o repositório também é um instrumento de apoio no desenvolvimento das atividades e permitirá desenvolver os fatores facilitadores que, segundo Pieracciani (2008), serve para "irradiar a inovação" na organização e reduzir os fatores inibidores tornando-se, assim, um componente decisivo para alcançar o objetivo da instituição.

Ainda neste contexto, considerando o desafio em inovar e avaliando a importância do diagnóstico para o sucesso da inovação, compreende-se que a metáfo-

\section{FATORES FACILITADORES || ||||||||||}

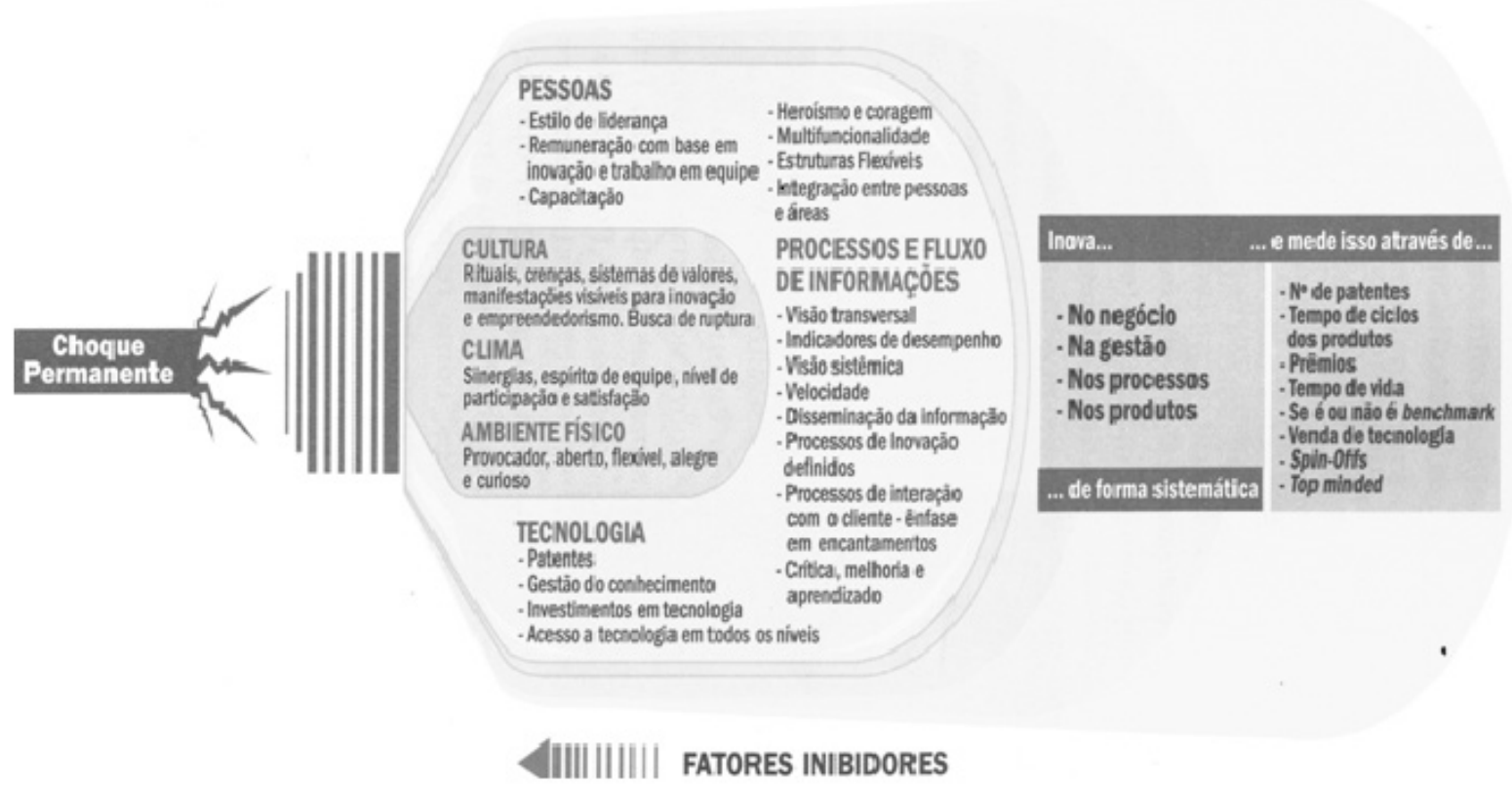

Figura 1: diagnóstico da empresa inovadora Fonte: Pieracciani (2008) 
ra da lâmpada também se aplica para identificar o repositório como fator motivador da inovação já que se observa nele a possibilidade em atuar nos seguintes fatores: pessoas, cultura, clima, ambiente físico, tecnologia, processos e fluxos de informações.

Como pode ser observado na Figura 1, em se tratando de inovação, o repositório desempenha um importante papel motivador, uma vez que fomenta o trabalho em equipe; na cultura por buscar a ruptura de valores antigos; no clima pelo aumento do nível de satisfação e de participação; no ambiente físico por tornar o ambiente provocador, aberto, flexível e por aguçar a curiosidade; na tecnologia ao possibilitar a gestão do conhecimento e o acesso a tecnologias em vários níveis, estruturas flexíveis e integração entre pessoas e áreas; e, por fim, nos processos e fluxos de informações por permitir uma visão transversal e sistêmica, gerar indicadores de desempenho, velocidade, disseminação da informação, crítica, melhoria e aprendizado. Consequentemente, permite a inovação de forma sistêmica no negócio, na gestão, nos processos e nos produtos da instituição científica, além de possibilitar medir por meio de estatísticas o uso, o acesso e a divulgação da produção científica.

Segundo Pieracciani (2008, p. 26), para se ter uma “estratégia voltada para a inovação é necessário ter uma cultura baseada na capacidade de se adaptar e tirar proveito do que é novo". O repositório vem sendo uma iniciativa das comunidades acadêmicas em identificar as possibilidades oferecidas pelas tecnologias como uma forma inovadora de oferecer serviços de in- formação por meio das mídias digitais que venham a apoiar as atividades ligadas ao ensino, à pesquisa e à comunicação científica. Segundo Meadows (1999, p. 1), "a maneira como o cientista transmite informações depende do veículo, da natureza das informações e do público alvo, [... ] com o passar do tempo, isso sofre mudanças, também sofrem alterações a formulação e o acondicionamento das informações”.

Pieracciani (2008, p. 26) afirma que a inovação pode ser "gerada por avanços tecnológicos ou demandas diretamente a partir da evolução de mercados”. A explosão informacional gerou a necessidade de melhorar os serviços oferecidos à instituição acadêmica e a evolução tecnológica possibilitou reestruturar a comunicação científica e permitir o tratamento rápido e eficaz de uma grande quantidade de informações, estes são considerados como principais demandas e necessidades que o repositório permite tratar de maneira rápida.

Mais do que necessária, a política da inovação tornou-se fundamental à sobrevivência das instituições que, a cada dia, ganha feições globalizadas. Segundo Pieracciani (2008) este é o atual lema das instituições que desejam se tornar competitivas. Para Burke (2003), a política não está fora do mundo acadêmico e este é o momento de ampliar a intenção e tecer discussões sobre a defesa do território intelectual, da resistência à inovação e voltar-se para a política do conhecimento no sentido da coleta, armazenamento, recuperação, e supressão da informação pelas autoridades, neste caso, a instituição científica.

\section{A IMPLANTAÇ̃̃O DO REPOSITÓRIO DA IES DO SENAI BAHIA}

A implantação do RI do SENAI Bahia tem como principal objetivo divulgar todo trabalho científico desenvolvido pela IES e por sua comunidade cientí- fica além de possibilitar a gestão do conhecimento científico e a disponibilização de um serviço de apoio à pesquisa. Considerando os atributos mencionados 
anteriormente, alguns autores defendem que os repositórios podem ser considerados um tipo de biblioteca digital. Com isso, Costa e Leite (2009) ressaltam a importância que a equipe responsável por sua implantação possua, a dimensão das implicações teóricas e práticas que envolvem o seu planejamento, implementação e funcionamento no âmbito de bibliotecas e institutos de pesquisa.

O planejamento do repositório envolve várias atividades que vão desde o planejamento, seleção do software até a elaboração das políticas que definirão o seu funcionamento. Para Costa e Leite (2009), as definições elaboradas no planejamento irão garantir o sucesso no desenvolvimento das atividades, por isso é necessário definir as etapas e prazos como pode ser visto na figura 2 permitindo que ele seja inserido no contexto da instituição.

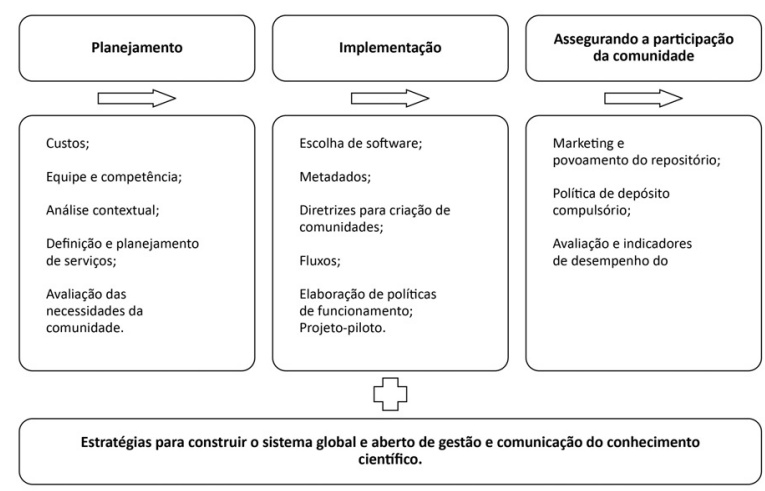

Figura 2: implantação do repositório

Fonte: Leite (2009)

Seguindo as orientações traçadas por Costa e Leite (2009) para a implementação do RI, foram divididas as atividades iniciais em 3 fases: $1^{\text {a }}$ fase, planejamento, cronograma, definição das comunidades e das competências; $2^{a}$ fase, configuração e instalação do software, definição das políticas, das comunidades e das coleções; e $3^{a}$ fase, teste do projeto piloto, divulgação e marketing e acompanhamento do indicador de desempenho.
Optou-se por utilizar, neste trabalho, o software Dspace, por ser uma plataforma apropriada para o desenvolvimento de Repositórios Institucionais para Acesso Livre ao Conhecimento nas Ciências e Humanidades. 0 termo “acesso livre”, segundo o glossário do IBICT, significa a livre disponibilização na internet de literatura de caráter científico, permitindo a qualquer utilizador pesquisar, consultar, descarregar, imprimir, copiar e distribuir o texto integral ou parcial de artigos e outras fontes de informação científica (IBICT, 2011).

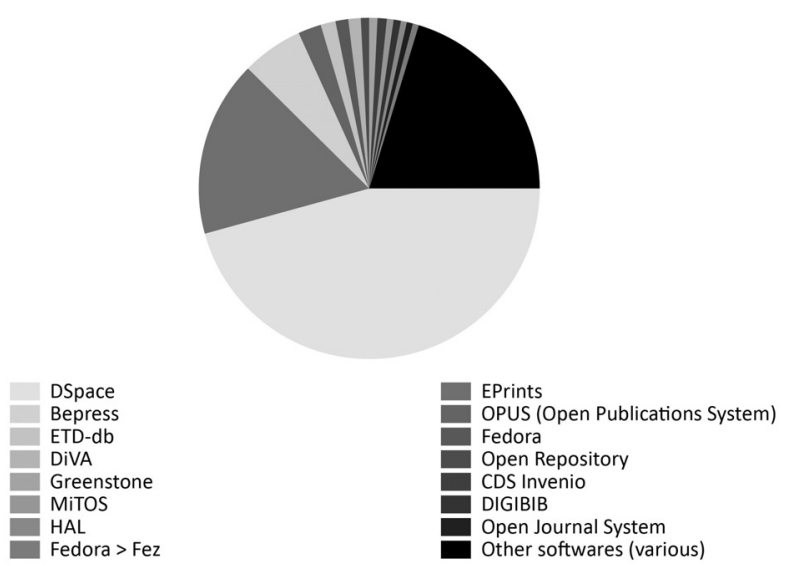

Figura 3: Repositórios internacionais registrados no ROAR

Fonte: http://roar.eprints.org. Acesso em: 23 fev 2012.

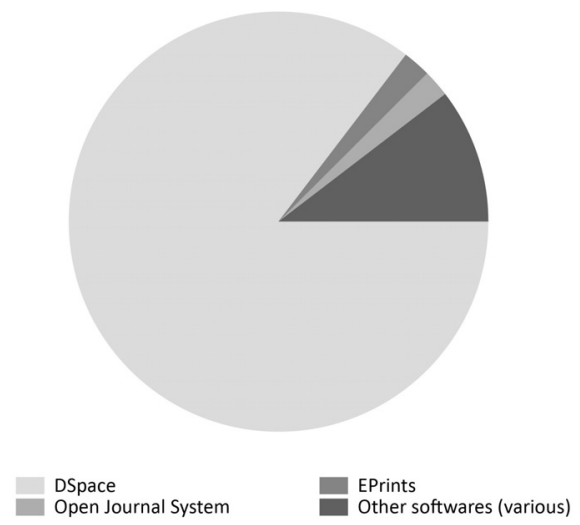

Figura 4: Repositórios brasileiros registrados no ROAR Fonte: http://roar.eprints.org. acesso em: 23 fev 2012. 
O Dspace é o software mais utilizado internacionalmente para implantação de repositórios com mais de $45 \%$ de aceitação. Esta realidade não é diferente no Brasil, que tem mais de $85 \%$ de aceitação das instituições, como pode ser visto nas Figuras 3 e 4. Estas informações podem ser verificadas no Registro de Repositórios de acesso livre (ROAR, sigla em inglês).

A implantação do repositório da IES do SENAI-BA implica em um importante trabalho participativo com a colaboração dos professores, bibliotecários, alunos e outros agentes sociais que interagem com a comunidade científica. 0 que constitui, por si só, uma forma de promover a aprendizagem cooperativa e a responsabilidade social entre todos os membros da comunidade acadêmica, resultando, assim, em uma rede do conhecimento científico.

De acordo com Castells (1999, p. 165), "o sistema de pesquisas acadêmicas é global. Depende da comunicação incessante entre os cientistas do mundo inteiro". Desse modo, torna-se importante disseminar a produção intelectual a nível global para atender a nova realidade da instituição. Assim sendo, após a aprovação do projeto, deu-se início ao seu planejamento levando ao conhecimento da gestão de tecnologia da informação para avaliar as necessidades tecnológicas para a implantação do Software Dspace.

A implantação foi dividida conforme as seguintes etapas: $1^{\text {a }}$ etapa - apresentação do repositório pelo bibliotecário na reunião dos colegiados (graduação e pós-graduação) da IES, sinalizando sua importância, seus objetivos e sua função; $2^{\mathrm{a}}$ etapa - definição das responsabilidades por parte da bibliotecária e da equipe de TI, contato com os professores feito pela bibliotecária com o objetivo de coletar informações que auxiliassem na construção da política de acesso, na preparação do termo de autorização às publicações e para o diagnóstico dos tipos de documentos produzidos pela Instituição e por parte dos técnicos de TI a avaliação dos hadwares da Instituição para certificar se está de acordo com as necessidades do software, definir os itens necessários para aquisição e instalação do software; $3^{a}$ etapa - submissão dos documentos (artigos, monografias, dissertações, partes de livros, vídeos, imagens) no repositório identificando-os de acordo com a política de conteúdo e de acesso das publicações que serão disponibilizadas no repositório e $4^{\mathrm{a}}$ etapa - a revisão dos metadados feita pelos bibliotecários para evitar erros de indexação.

O Dspace possibilita que a instituição crie o repositório de maneira que modelem sua estrutura para atender às suas necessidades. Pensando em adequar o Dspace à Instituição, optou-se por adotar o sistema de comunidades, divididas em Graduação, Pós-Graduação latu sensu, Pós-Graduação stritu sensu, centro de pesquisa e cursos técnicos; divididas em subcomunidades e agrupando-as por cursos e coleções, sendo esta ultima definida pelos tipos de documentos depositados no repositório.

\subsection{POLÍTICA DE ACESSO LIVRE: REPOSITÓRIO DA IES DO SENAI- BAHIA}

Para a implantação do Repositório, será necessária definir algumas ações a serem efetuadas pelos administradores, os tipos de documentos que serão disponibilizados para arquivamento no repositório da

Instituição, sugerir a criação de um regulamento para estabelecer a política de arquivamento e descrever as etapas de implantação do RI. 


\begin{tabular}{|l|l|}
\hline \multicolumn{1}{|c|}{ AÇÃo } & \multicolumn{1}{c|}{ DESCRIÇão } \\
\hline $\begin{array}{l}\text { Customização do formulário de } \\
\text { entrada do Dspace }\end{array}$ & $\begin{array}{l}\text { Adequar o formulário de entrada do Dspace que atenda às necessidades da } \\
\text { Instituição e que esteja de acordo com as políticas de conteúdo do RI. Definir } \\
\text { e levantar os metadados, associá-los de acordo com o padrão Dublin Core e } \\
\text { ajustes para a entrada dos dados. }\end{array}$ \\
\hline Implantação do RI. & $\begin{array}{l}\text { Adequação do layout do sistema à proposta do RI, tornando-o um ambiente } \\
\text { amigável e que garanta a funcionalidade do sistema. }\end{array}$ \\
\hline Configuração das comunidades & $\begin{array}{l}\text { Baseando-se nas políticas de conteúdo e utilizando os recursos do sistema, } \\
\text { elaborar uma estrutura de submissão e preservação de documentos. Organi- } \\
\text { zar o RI de acordo com as comunidades (Graduação, Pós-Graduação latu sen- } \\
\text { su, Pós-Graduação stritu sensu, centro de pesquisa e cursos técnicos). Fica } \\
\text { sob responsabilidade de cada comunidade a organização de seus documentos } \\
\text { em coleções baseando-se na política do RI. }\end{array}$ \\
\hline Criação do grupo gestor & $\begin{array}{l}\text { Criar uma portaria definindo os representantes do Grupo gestor do RI com } \\
\text { representantes das faculdades, Biblioteca, Informática. }\end{array}$ \\
\hline $\begin{array}{l}\text { Encaminhamento ao Diretor Ins- } \\
\text { tituição da proposta de política } \\
\text { para o RI. }\end{array}$ & $\begin{array}{l}\text { Apresentar ao diretor da instituição a proposta da política do RI para sua apro- } \\
\text { vação e posterior aprovação da CES. }\end{array}$ \\
\hline
\end{tabular}

Fonte: Adaptação de Rosa (2010)

Toda produção científica depositada no repositório deverá estar de acordo com a política de conteúdo, respeitando às questões relacionadas com os direitos de propriedade intelectual, para que, desta maneira, a Instituição possa ter diretrizes que assegurem as boas práticas.

A elaboração de um regulamento, definindo os representantes do grupo gestor do RI composto por representantes da IES, será necessário para formalizar a criação do RI e estabelecer uma política de arquivamento para garantir a formação, desenvolvimento e acesso às coleções por um prazo permanente. A política do repositório é constituída de recomendações que orientam desde a implantação até o seu gerenciamento, definidos pelos administradores durante o planejamento e alinhadas de acordo com a sua finalidade.
As políticas de funcionamento do Rl abrangem orientações sobre a definição de conteúdo, de acesso e submissão, contemplando vários aspectos, desde os mais gerais, como por exemplo, os tipos de documentos e formatos de arquivos a serem aceitos, até questões mais específicas como os metadados a serem implementados, a permissão de acesso aos itens e também das etapas necessárias para disponibilizar um documento, as políticas devem estar explicitas e disponíveis para os usuários no próprio repositório, facilitando o acesso e o uso do mesmo (SHINTAKU; MEIRELLES, 2010).

A customização e adaptação do software Dspace será de acordo com os padrões da Instituição sob a coordenação dos administradores, visando torná-lo 
um ambiente amigável e que garanta a funcionalidade do sistema, tornando-o uma representação da Instituição no meio acadêmico. Desta maneira, pretende-se, com a implantação do RI, que a IES do SENAI Bahia ocupe uma posição no Ranking Web ad- ministrada pelo ROAR, competindo com as universidades do mundo, melhorando sua visibilidade entre as demais universidades e tornando-se competitiva entre as instituições de Ensino Superior da América Latina e do Brasil.

\section{CONSIDERAÇÕES FINAIS}

A Proposta de implantação do RI do SENAI Bahia é uma iniciativa da Biblioteca do Centro de Manufatura tecnológica (CIMATEC), que levou a ideia à direção da IES e após sua aprovação deu início à sensibilização de outros setores importantes no desenvolvimento do projeto, sendo eles: Setor de Informática e do Colegiado da IES. O projeto encontra-se em fase de elaboração de suas políticas, nas definições das comunidades, dos serviços oferecidos e dos tipos de documentos que serão indexados em seu acervo. A área de TI está responsável pela instalação do Dspace na infra-estrutura da instituição.

\section{REFERÊNCIAS}

ANDRADE, Vitor. Repositório Institucional da UFBA ganha concurso nacional. Impressão digital. 126. 2011. Disponível em: http://impressaodigital126. com. br/2011/12/12/repositorio-institucional-da-ufba-ganha-concurso-nacional/. Acesso em: 5 jan. 2011.

BURKE, Peter. Uma história social do conhecimento: de Gutemberg a Diderot. Rio de Janeiro: Jorge Zahar Editor, 2003.

CASTELLS, Manuel. A sociedade em rede. Tradução de Roneide Venancio Majer, 13. ed. São Paulo: Paz e Terra, 1999.
Para que a IES do SENAI tenha sucesso e alcance os objetivos traçados, é necessário o envolvimento da direção da instituição na construção das políticas e da disponibilização dos recursos. 0 projeto piloto deverá estar disponível para teste até final do mês de maio, logo após sua aprovação dará início ao povoamento do repositório e, por último será, feito a divulgação por meio do marketing com seminários, envio de e-mails, disponibilização de Baners na intranet etc.

COSTA, Sely Maria de Souza; LEITE, Fernando Cesar Lima. Insumos conceituais e práticos para iniciativas de repositórios institucionais de acesso aberto à informação científica em bibliotecas de pesquisa. In: SAYÃO, Luis (org. ); et al. Implantação e gestão de repositórios institucionais: políticas, memória, livre acesso e preservação. Salvador: EDUFBA, 2009.

\section{GIL, Antonio Carlos. Como elaborar projetos de pes-} quisa, São Paulo: Atlas, 2010

HOMMERDING, Nádia M. S. ; VERGUEIRO, Valdomiro. Profissionais da informação e o mapeamento do conhecimento nas organizações: o caso da KPMG 
Brasil. Revista digital de Biblioteconomia e Ciência da Informação, Campinas, v. 2, n. 1, p. 17-36, jul. /dez. 2004. Disponível em: http://www. sbu. unicamp. br/seer/ojs/index. php/sbu_rci/article/viewFile/300/179. Acesso em: 6 ago. 2010.

IBICT. DSpace: Repositórios Digitais. Disponível em: <http://dspace. ibict. br/index. php?option=com_ frontpage\&ltemid=1>. Acesso em: 21 nov. 2011.

MEADOWS, A. J. A comunicação científica. Tradução, Antônio Agenor Briquet de Lemos. Brasília, DF. : Briquet de Lemos, 1999.

PIERACCIANI, Valter. Usina de inovações: guia prático para transformação da sua empresa. São Paulo: Canal Certo, 2008.

ROSA, Flávia. A disseminação da produção científica da Universidade Federal da Bahia através da implantação do seu repositório institucional: uma política de acesso aberto. 2011, 242f. Tese (Doutora- do em cultura e sociedade) - Universidade Federal da Bahia, Faculdade de Comunicação, Salvador, 2011. Disponível em: https://repositorio. ufba. br/ri/bitstream/ri/3031/1/Tese\%20Flavia. pdf. Acesso em: 20 dez. 2011.

ROSA, Flávia; GOMES, Maria João; PALÁCIOS, Marcos. Políticas de acesso livre para a UFBA: partilhando experiências do RepositóriUM. In: Encontro de Estudos Multidisciplinares em Cultura, 6, Bahia, 2010. Disponível em: https://repositorio. ufba. br/ri/bitstream/ri/1960/1/TEXTO_ENECULT_26_fev. pdf. Acesso em: 20 dez. 2011.

SALIBI NETO, José. Alerta vermelho permanente. HSM Management, São Paulo, v. 4, n. 75, p. 116-123, 2009.

SHINTAKU, Milton; MEIRELLES, Rodrigo. Manual do DSPACE : administração de repositórios. Salvador: EDUFBA, 2010. 83 p. Disponível em: http://www. repositorio. ufba. br/ri/handle/ri/769. Acesso em: 10 nov. 12. 